\title{
Inhibitory Effects of Two Ferulates from Angelica Sinensis on Platelet Aggregation and Oxytocin-induced Uterine Contraction
}

\author{
Y. Yu ${ }^{1}$, B. Q. $\operatorname{Lin}^{1}$, L. Yu ${ }^{2}$, Y. Q. Hua ${ }^{2}$, J. A. Duan ${ }^{2}$ and S. P. $\operatorname{Li}^{1,2, *}$ \\ ${ }^{1}$ Institute of Chinese Medical Sciences, University of Macau, Macao SAR, China \\ ${ }^{2}$ Jiangsu Key Laboratory for TCM Formulae Research, Nanjing University of Chinese Medicine, Nanjing, China
}

\begin{abstract}
Ferulic acid (FA) is widely considered as a biologically active component in Angelica sinensis, and used as one of the marker compounds for the quality control of Angelica sinensis. However, in A. sinensis, FA mainly exists as its ester, coniferyl ferulate (CF). CF is unstable and readily hydrolyzed into FA during conventional extraction. Herein, their antiplatelet aggregation activities and relaxant effects on oxytocin-induced mouse uterine muscle contraction were investigated and compared. The results showed that FA inhibited arachidonic acid (AA), adenosine diphosphate (ADP) and thrombin (THR)-induced platelet aggregation with $\mathrm{IC}_{50}$ values of $974.8 \pm 97.5,737.9 \pm 40.2$ and $244.6 \pm 25.6 \mu \mathrm{g} / \mathrm{ml}$, respectively. The potency of $\mathrm{CF}$ is much higher than that of $\mathrm{FA}$, and the $\mathrm{IC}_{50}$ values for AA, ADP and THR were 7.1 \pm 0.3 , $276.4 \pm 53.4$ and $77.5 \pm 23.1 \mu \mathrm{g} / \mathrm{ml}$, respectively. $\mathrm{IC}_{50}$ of FA was $23.8 \pm 6.2 \mu \mathrm{g} / \mathrm{ml}$ for oxytocin-induced uterine contraction in vitro. $\mathrm{CF}$ could only be tested at low concentration and its $\mathrm{IC}_{50}$ could not be calculated thereafter because of its strong hydrophobic property. So CF has more potent antiplatelet aggregation activity, while FA has stronger inhibitory effect on oxytocin-induced uterine contraction in vitro.
\end{abstract}

Keywords: Angelica sinensis, coniferyl ferulate, ferulic acid, antiplatelet aggregation, oxytocin-induced uterine contraction.

\section{INTRODUCTION}

Angelica sinensis, known as Danggui in China, has been used for thousand years as traditional Chinese, Korean, and Japanese medicine. Nearly $19 \%$ of the traditional Chinese medicinal preparations recorded in Chinese Pharmacopeia (2005 edition) contain A. sinensis. A. sinensis can enrich blood, activate blood circulation, regulate menstruation, relieve pain, and relax bowels, and is used for the treatment of anemia with dizziness and palpitation, amenorrhea, dysmenorrhea, constipation, rheumatic arthralgia, traumatic injuries, carbuncles, boils and sores [1]. Modern studies have shown that $A$. sinensis has multiple pharmacological activities [2], including anti-inflammatory [3], antioxidant [4], immunostimulative [5], antiplatelet aggregation [6], antitumor [7, 8] and estrogenic [9] activities. Ferulic acid (FA) is usually considered as a biologically active component, and has been used as one of the marker compounds for the quality control of $A$. sinensis [1]. Indeed, FA has antioxidant [10], anti-inflammatory [11], antitumor [12], anti-diabetes [13], antimicrobial [14], anti-hypertension and antihyperlipidemia [15] activities, and protective effect on ironand nicotine-induced toxicity [16, 17]. However, in A. sinensis, FA mainly exists as its ester, coniferyl ferulate (CF). CF is unstable and readily hydrolyzed into FA during conventional extraction $[18,19]$ although $\mathrm{CF}$ also has antineoplastic [20], antibacterial [21] and antioxidant [22] effects. So it is interesting to investigate and compare their potency of

*Address correspondence to this author at the Institute of Chinese Medical Sciences, University of Macau, Macao SAR, China; Tel: +853-8397 4692; Fax: +853-2884 1358; E-mail: LISHAOPING@HOTMAIL.COM pharmacological activities, which will help to improve clinical uses of $A$. sinensis.

In the present study, antiplatelet aggregation and uterusregulating activities of FA and $\mathrm{CF}$, two ferulates related to $A$. sinensis, were investigated and compared.

\section{MATERIALS AND METHODS}

\section{Materials}

Arachidonic acid (AA), adenosine diphosphate (ADP) and FA (Fig. 1A) were purchased from Sigma (St. Louis, MO, USA). Thrombin (THR) was the product of Dade Behring (Eschborn, Germany). Disposable cuvettes for antiplatelet aggregation assay were from SUCCESS Technology Development Co. Ltd (Beijing, China). Deionized water was prepared using a Millipore Milli Q-Plus system (Millipore, Billerica, MA, USA). All other chemicals not mentioned here were analytical grade from standard sources. CF (purity $>95.0 \%$ determined by HPLC, Fig. 1B) was separated and purified from essential oil of $A$. sinensis in our lab [23]. The structure of CF was confirmed by its UV, MS, ${ }^{1} \mathrm{H}-\mathrm{NMR}$ and ${ }^{13} \mathrm{C}-\mathrm{NMR}$ data $[19,24]$.

\section{Animals}

The experiments were performed in accordance with the Animal Ethics Committee of Nanjing University of Chinese Medicine. Male New Zealand white rabbits (1.8-2.5 kg) and non-pregnant sexually mature female Kunming mice (6-7 weeks, 18-22 g) were obtained from Experimental Animal Center, Nanjing University of Chinese Medicine. All animals were maintained on a pellet diet and water ad libitum 
and kept under the laboratory condition of light/dark cycle $12 / 12$ hours.

A<smiles>Cc1cc(/C=C/C(=O)O)ccc1O</smiles>

B<smiles>COc1cc(/C=C/C=C/C(=O)OC/C=C/c2ccc(O)c(OC)c2)ccc1O</smiles>

Fig. (1). Chemical structures of ferulic acid (FA) and coniferyl ferulate $(\mathrm{CF})$.

\section{Antiplatelet Aggregation Assay in vitro}

Rabbit platelets were used for antiplatelet aggregation assays. Blood from the rabbit carotid artery was collected in plastic tubes and anticoagulated with $3.2 \%$ sodium citrate solution $(9: 1, \mathrm{v} / \mathrm{v})$. The blood sample was centrifuged at 100 $\times \mathrm{g}$ for $10 \mathrm{~min}$, platelet rich plasma was obtained. Then the precipitate was centrifuged at $1,925 \times \mathrm{g}$ for another $10 \mathrm{~min}$ to obtain platelet poor plasma. The final count of platelets in platelet rich plasma was adjusted to $7 \times 10^{9}$ cells $/ \mathrm{ml}$ with platelet poor plasma.

FA and CF were dissolved in dimethyl sulfoxide. Stock solutions of AA, ADP and THR were prepared with 1\% sodium bicarbonate solution, phosphate buffer solution and deionized water, respectively.

Antiplatelet aggregation assays were performed by turbidimetric method [25] on a SC-2000 aggregometer (SUCCESS Technology Development Co. Ltd, Beijing). The test samples were pre-incubated with platelets for $5 \mathrm{~min}$ at $37^{\circ} \mathrm{C}$. Then the platelet aggregation was induced by addition of AA, ADP or THR solution with final concentration of 330 $\mu \mathrm{M}, 15 \mu \mathrm{M}$ and $0.3 \mathrm{IU}$, respectively. All tests were performed within $3 \mathrm{~h}$ after the collection of blood. Corresponding solvents were used as blank controls for the corresponding test. The antiplatelet aggregation potency is expressed as inhibition (\%) which was calculated as follows:

$$
\text { Inhibition } \%=(A-B) / A \times 100 \%
$$

where $\mathrm{A}$ and $\mathrm{B}$ were the absorbance values of corresponding blank controls and test samples, respectively.

\section{Oxytocin-induced Uterine Contraction Assay in vitro}

Oxytocin-induced female mice uterine contraction assay was tested in vitro [26]. In brief, synchronistically estrus mice were pretreated with estradiol benzoate $(5 \mathrm{mg} / \mathrm{kg}$, s.c. $)$ $24 \mathrm{~h}$ prior to the study. On the third day, the mice were sacrificed by cervical dislocation and the uteri were isolated. The whole uterus was taken as one sample. The cervical end was tied to perspex holder, and the two ovarian ends were put together as another end tied to an isometric force transducer. A resting tension of $1 \mathrm{~g}$ was applied for superfusion with oxygenated Krebs $\left(95 \% \mathrm{O}_{2}, 5 \% \mathrm{CO}_{2}, \mathrm{pH} 7.3\right)$ at $37{ }^{\circ} \mathrm{C}$. Equilibration period was not less than $45 \mathrm{~min}$. After establishing a steady basal tone, oxytocin $(5 \mathrm{U} / \mathrm{ml})$ was added to baths. Once the contraction reached a plateau, FA and CF of cumulative concentrations were added to organ bath with an interval of about 10 min. Dimethyl sulfoxide (3\%o) was taken as vehicle control. Contractions were recorded by Power$\mathrm{Lab} / 8 \mathrm{~s}$ data recording system (AD Instruments, Australia) which was linked to a mackintosh computer (Powermac 7200/120, Apple, USA) where Chart software (v. 4.2.2 AD Instruments, Australia) was used to display and measure the tension changes of tissues. Antioxytocin effects were expressed as a percentage of relaxation based on $5 \mathrm{U} / \mathrm{ml}$ oxytocin-induced plateau contraction.

\section{Statistical Analysis}

Data were expressed as the mean \pm SD and presented as an average of three replicates. The $\mathrm{IC}_{50}$ (the concentration that providing $50 \%$ inhibition) values were calculated based on linear regression of the inhibitory capacities to the concentrations or the logistics of concentration.

\section{RUSULTS AND DISCUSSION}

\section{The Effects of FA and CF on Platelet Aggregation in vitro}

Both FA and CF concentration-dependently inhibited AA, ADP and THR-induced platelet aggregations. As shown in Table 1, FA inhibited platelet aggregation induced by AA, $\mathrm{ADP}$ and THR with $\mathrm{IC}_{50}$ values of $974.8 \pm 97.5,737.9 \pm$ 40.2 and $244.6 \pm 25.6 \mu \mathrm{g} / \mathrm{ml}$, respectively. The potency of $\mathrm{CF}$ is much higher than that of $\mathrm{FA}$, and the $\mathrm{IC}_{50}$ values for AA, ADP and THR were $7.1 \pm 0.3,276.4 \pm 53.4$ and $77.5 \pm$ $23.1 \mu \mathrm{g} / \mathrm{ml}$, respectively. The results of FA agreed with Ou's report which also showed that FA had antiplatelet aggregation effect [27]. The results accounted for the antiplatelet aggregation mechanism of $A$. sinensis injection [6] and activation blood circulation mechanism of $A$. sinensis [1]. $\mathrm{CF}$ had stronger effect than FA, but $\mathrm{CF}$ is unstable and readily hydrolyzed into FA during conventional extraction, which indicates that we should improve extraction method to reduce such hydrolysis when $A$. sinensis was mainly used to improve platelet aggregation.

\section{The Effects of FA and CF on Oxytocin-induced Uterine Contraction in vitro}

Oxytocin, a nonapeptide hormone, induces uterine and mammary gland contractions. Both tissues express oxytocin receptors. The number of these receptors is increased by estrogen and decreased by progesterone [28]. So the mice were pretreated with estradiol benzoate $24 \mathrm{~h}$ prior to the study to increase the oxytocin receptor numbers and thus increase the sensitivity of uterine to the stimulation of oxytocin in vitro.

The results showed that both FA and CF inhibited oxytocin-induced uterine contraction in a concentration-dependent manner, and FA had more potent inhibitory effect than $\mathrm{CF}$ (Fig. 2). Actually, the concentration-dependent response of CF only could be found when the concentration beyond 25 $\mu \mathrm{g} / \mathrm{ml}$ according to Fig. (2), and the concentrations of $\mathrm{CF}$ below $25 \mu \mathrm{g} / \mathrm{ml}$ had no obvious inhibition on oxytocininduced mice uterine contraction. $\mathrm{IC}_{50}$ of FA was $23.8 \pm 6.2$ 
Table 1. Inhibitory Effects of FA and CF on Rabbit Platelet Aggregation Induced by AA (330 $\mu$ M), ADP (15 $\mu$ M) and THR (0.3 $\mathrm{U} / \mathrm{ml}$ ) In Vitro

\begin{tabular}{|c|c|c|}
\hline \multicolumn{3}{|l|}{$\mathbf{A A}$} \\
\hline Test range $(\mu \mathrm{g} / \mathrm{ml})$ & $101.0-1619.4^{\mathrm{a}}$ & $2.3-37.6$ \\
\hline Linear range $(\mu \mathrm{g} / \mathrm{ml})$ & $101.0-1619.4$ & $2.3-37.6$ \\
\hline $\mathbf{R}^{2}$ & 0.984 & 0.949 \\
\hline $\mathrm{IC}_{50}(\mu \mathrm{g} / \mathrm{ml})$ & $974.8 \pm 97.5$ & $7.1 \pm 0.3$ \\
\hline \multicolumn{3}{|l|}{ ADP } \\
\hline Test range $(\mu \mathrm{g} / \mathrm{ml})$ & $202.4-1215.0$ & $19.0-303.2$ \\
\hline $\mathbf{R}^{2}$ & 0.903 & 0.995 \\
\hline $\mathrm{IC}_{50}(\mu \mathrm{g} / \mathrm{ml})$ & $737.9 \pm 40.2$ & $276.4 \pm 53.4$ \\
\hline \multicolumn{3}{|l|}{ THR } \\
\hline Test range $(\mu \mathrm{g} / \mathrm{ml})$ & $25.2-403.9$ & $19.0-303.2$ \\
\hline Linear range $(\mu \mathrm{g} / \mathrm{ml})$ & $25.2-403.9$ & $19.0-303.2$ \\
\hline Regression equation & $Y^{b}=136.39 x+16.66$ & $Y^{c}=62.03 x-66.61$ \\
\hline $\mathbf{R}^{2}$ & 0.950 & 0.939 \\
\hline $\mathrm{IC}_{50}(\mu \mathrm{g} / \mathrm{ml})$ & $244.6 \pm 25.6$ & $77.5 \pm 23.1$ \\
\hline
\end{tabular}

$\mathrm{IC}_{50}$ values were expressed as the mean $\pm \mathrm{SD}$ and presented as an average of three replicates.

${ }^{a}$ The actual tested samples were obtained with serial double dilution through the highest to lowest concentration of samples except FA (202.4, 404.8, 485.8, 809.7 and 1215.0 $\left.\mu \mathrm{g} / \mathrm{ml}\right)$ for ADP-induced platelet aggregation assay.

${ }^{\mathrm{b}}$ Regression equations were expressed as inhibition $\%$ vs. concentration $(\mathrm{mg} / \mathrm{ml})$.

${ }^{\mathrm{c}}$ Regression equation were as inhibition $\% v s$. the logistic of concentration $(\mu \mathrm{g} / \mathrm{ml})$.

$\mu \mathrm{g} / \mathrm{ml}$. Potent prostaglandins and potent leukotrienes play an important role in generating primary dysmenorrhea symptoms [29], so the anti-inflammatory effect of $A$. sinensis may help to treat dysmenorrhea [3]. Moreover, in non-pregnant women, the oxytocin receptor density varies over the menstrual cycle and increases markedly at the onset of menstruation. So blocking the uterine oxytocin receptor can inhibit primary dysmenorrhoea [30]. Therefore, the potent antispasm activity of FA on oxytocin-induced uterine contraction could also partly elucidate the anti-dysmenorrhea mechanism of $A$. sinensis. Since CF has strong hydrophobic property, it could only be tested at low concentration and its $\mathrm{IC}_{50}$ could not be calculated thereafter. The results suggest that FA is a good form when $A$. sinensis is used to inhibit the oxytocin-induced uterine contraction.

In conclusion, the pharmacological activities of two ferulates, FA and $\mathrm{CF}$, had their own characters. CF has more potent antiplatelet aggregation activity, while FA has stronger inhibitory effect on oxytocin-induced uterine contraction. The results suggest that different extraction methods of $A$. sinensis are necessary according to its different treatment purposes.

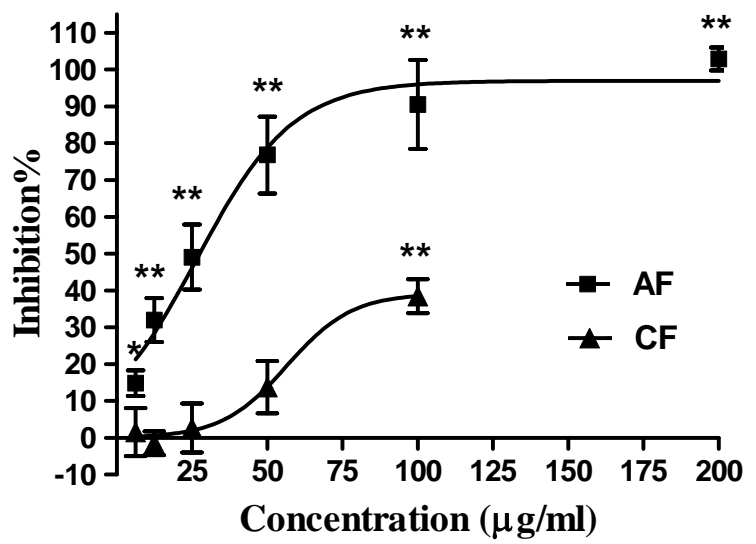

Fig. (2). The inhibitory effects of $F A$ and $C F$ on oxytocininduced mice uterine muscle contraction in vitro. The data were expressed as mean \pm SD of three replicates. ${ }^{*} P<0.05$ and $* * P<0.01$ vs. vehicle control.

\section{ACKNOWLEDGEMENTS}

The research was supported by grants from Jiangsu Key Laboratory for TCM Formulae Research, Nanjing University 
of Chinese Medicine (No.022021014003) and University of Macau (RG083/07-08S) to S.P. Li.

\section{REFERENCES}

[1] The State Pharmacopoeia Commission of the People's Republic of China. Pharmacopoeia of the People's Republic of China. Chemical Industry press: Beijing, 2005, vol. 1, p. 89.

[2] Xia, Q.; Zhang, P.; Li, S.P.; Wang, Y.T. The pharmacological progress of the study on Angelica sinensis. Lishizhen Med. Mater Med Res., 2004, 15(3), 164-166.

[3] Xie, C.H.; Zhang, M.S.; Zhou, Y.F.; Han, G.; Cao, Z.; Zhou, F.X.; Zhang, G.; Luo, Z.G.; Wu, J.P.; Liu, H.; Chen, J.; Zhang, W.J. Chinese medicine Angelica sinensis suppresses radiation-induced expression of TNF- $\alpha$ and TGF- $\beta 1$ in mice. Oncol. Rep., 2006, 15(6), 1429-1436.

[4] Wu, S.J.; Ng, L.T.; Lin, C.C. Antioxidant activities of some common ingredients of traditional Chinese medicine, Angelica sinensis, Lycium barbarum and Poria cocos. Phytother. Res., 2004, 18(12), 1008-1012.

[5] Yang, T.H.; Jia, M.; Meng, J.; Wu, H.; Mei, Q. Immunomodulatory activity of polysaccharide isolated from Angelica sinensis. Int. J. Biol. Macromol., 2006, 39(4-5), 179-184.

[6] Dong, W.G.; Liu, S.P.; Zhu, H.H.; Luo, H.S.; Yu, J.P. Abnormal function of platelets and role of Angelica sinensis in patients with ulcerative colitis. World J. Gastroenterol., 2004, 10(4), 606609.

[7] Cheng, Y.L.; Chang, W.L.; Lee, S.C.; Liu, Y.G.; Cheng, J.C.; Lin, S.Z.; Tsai, N.M.; Yu, D.S.; Yen, C.Y.; Harn, H.J. Acetone extract of Angelica sinensis inhibits proliferation of human cancer cells via inducing cell cycle arrest and apoptosis. Life Sci., 2004, 75(13), 1579-1594.

[8] Tsai, N.M.; Lin, S.Z.; Lee, C.C.; Chen, S.P.; Su, H.C.; Chang, W.L.; Harn, H.J. The antitumor effects of Angelica sinensis on malignant brain tumors in vitro and in vivo. Clin. Cancer. Res., 2005, 11(9), 3475-3484.

[9] Circosta, C.; Pasquale, R.D.; Palumbo, D.R.; Samperi, S.; Occhiuto F. Estrogenic activity of standardized extract of Angelica sinensis. Phytother. Res., 2006, 20(8), 665-669.

[10] Thyagaraju, B M.; Muralidhara. Ferulic Acid supplements abrogate oxidative impairments in liver and testis in the streptozotocindiabetic rat. Zoolog. Sci., 2008, 25(8), 854-860.

[11] Cheng, C.Y.; Ho, T.Y.; Lee, E.J.; Su, S.Y.; Tang, N.Y.; Hsieh, C.L. Ferulic Acid reduces cerebral infarct through its antioxidative and anti-inflammatory effects following transient focal cerebral ischemia in rats. Am. J. Chin. Med., 2008, 36(6), 1105-1119.

[12] Alias, L.M.; Manoharan, S.; Vellaichamy, L.; Balakrishnan, S.; Ramachandran, C.R. Protective effect of ferulic acid on 7, 12dimethylbenz[a]anthracene-induced skin carcinogenesis in Swiss albino mice. Exp. Toxicol. Pathol., 2009, 61(3), 205-214.

[13] Mandal, S.; Barik, B.; Mallick, C.; De, D.; Ghosh, D. Therapeutic effect of ferulic acid, an ethereal fraction of ethanolic extract of seed of Syzygium cumini against streptozotocin-induced diabetes in male rat. Methods Find. Exp. Clin. Pharmacol., 2008, 30(2), 121-128.

[14] Gardjeva, P.A.; Dimitrova, S.Z.; Kostadinov, I.D.; Murdjeva, M.A.; Peyche, L.P.; Lukanov, L.K., Stanimirova, I.V.; Alexandrov, A.S. A study of chemical composition and antimicrobial activity of Bulgarian propolis. Folia Med. (Plovdiv), 2007, 49(3-4), 63-69.
[15] Ardiansyah; Ohsaki, Y.; Shirakawa, H.; Koseki, T.; Komai, M. Novel effects of a single administration of ferulic acid on the regulation of blood pressure and the hepatic lipid metabolic profile in stroke-prone spontaneously hypertensive rats. J. Agric. Food Chem., 2008, 56(8) 2825-2830.

[16] Chao, H.M.; Chen, Y.H.; Liu, J.H.; Lee, S.M.; Lee, F.L.; Chang, Y.; Yeh, P.H.; Pan, W.H.; Chi, C.W.; Liu, T.Y.; Lui, W.Y.; Ho, L.T.; Kuo, C.D.; Lin, D.E.; Chan, C.C.; Yang, D.M.; Lin, A.M.; Chao, F.P. Iron-generated hydroxyl radicals kill retinal cells in vivo: effect of ferulic acid. Hum. Exp. Toxicol., 2008, 27(4), 327339.

[17] Adluri, R.S.; Nagarajan, D.; Periyaswamy, V.; Venugopal, P.M. Dose-response effect of ferulic acid against nicotine-induced tissue damage and altered lipid levels in experimental rats: a pathohistological evaluation. Fundam. Clin. Pharmacol., 2008, 22(5), 557567.

[18] Lu, G.H.; Chan, K.; Leung, K.; Chan, C.L.; Zhao, Z.Z.; Jiang, Z.H. Assay of free ferulic acid and total ferulic acid for quality assessment of Angelica sinensis. J. Chromatogr. A., 2005, 1068(2), 209219.

[19] Xie, J.J.; Lu, J.; Qian, Z.M.; Yu, Y.; Duan, J.A.; Li, S.P. Optimization and comparison of five methods for extraction of coniferyl ferulate from Angelica sinensis. Molecules, 2009, 14(1), 555-565.

[20] Kong, L.; Yu, Z.; Bao, Y.; Su, X.; Zou, H.; Li, X. Screening and analysis of an antineoplastic compound in Rhizoma Chuanxiong by means of in vitro metabolism and HPLC-MS. Anal. Bioanal. Chem., 2006, 386(2), 264-274.

[21] Chou, S.C.; Everngam, M.C.; Sturtz, G.; Beck, J.J. Antibacterial activity of components from Lomatium californicum. Phytother. Res., 2006, 20(2), 153-156.

[22] Li, S.Y.; Yu, Y.; Li, S.P. Identification of antioxidants in essential oil of Radix Angelicae sinensis using HPLC coupled with DADMS and ABTS-based assay. J. Agric. Food Chem., 2007, 55(9), 3358-3362.

[23] Lin, L.Z.; He, X.G.; Lian, L.Z.; King, W.; Elliott, J. Liquid chromatographic-electrospray mass spectrometric study of the phthalides of Angelica sinensis and chemical changes of Zligustilide. J. Chromatogr. A, 1998, 810(1-2), 71-79.

[24] Lu, X.H.; Zhang, J.J.; Liang, H.; Zhao, Y.Y. Chemical constituents of Angelica sinensis. J. Chin. Pharmaceut. Sci., 2004, 13(1), 1-3.

[25] Born, G.V.R. Aggregation of blood platelets by adenosine diphosphate and its reversal. Nature, 1962, 194(4832), 927-929.

[26] Chao, J.; Buse, J.; Shimamoto, K.; Margolius, H.S. Kallikreininduced uterine contraction independent of kinin formation. Proc. Natl. Acad. Sci. USA, 1981, 78(10), 6154-6157.

[27] Ou, S.; Kwok, K.C. Ferulic acid: pharmaceutical functions, preparation and applications in food. J. Sci. Food Agric., 2004, 84(11), 1261-1269.

[28] Parker, K.L.; Schimmer, B.P. In Pituitary Hormones and Their Hypothalamic Releasing Factors; Brunton, L.L.; Lazo, J.S.; Parker, K.L., Ed.; Goodman \& Gilman's the Pharmacological Basis of Therapeutics, McGraw-Hill: New York, 2006; pp. 1489-1510.

[29] Harel, Z. Dysmenorrhea in adolescents and young adults: from pathophysiology to pharmacological treatments and management strategies. Expert. Opin. Pharmacother., 2008, 9(15), 2661-2672.

[30] Akerlund, M. Vasopressin and oxytocin in normal reproduction and in the pathophysiology of preterm labour and primary dysmenorrhoea. Development of receptor antagonists for therapeutic use in these conditions. Rocz. Akad. Med. Bialymst., 2004, 49, 18-21.

This is an open access article licensed under the terms of the Creative Commons Attribution Non-Commercial License (http://creativecommons.org/licenses/ by-nc/3.0/) which permits unrestricted, non-commercial use, distribution and reproduction in any medium, provided the work is properly cited. 